\title{
AETIOLOGY AND CLINICAL PROFILE OF CIRRHOSIS OF LIVER IN A TERTIARY CARE CENTRE OF KARNATAKA
}

Parvesh Kumar Jain ${ }^{1}$, Hemachandra P2

${ }^{1}$ Associate Professor, Department of Medical Gastroenterology, Bangalore Medical College and Research Institute, Bangalore. ${ }^{2}$ Assistant Professor, Department of Medicine, Bangalore Medical College and Research Institute, Bangalore.

ABSTRACT
BACKGROUND
Aetiology and clinical profile of cirrhosis of liver may vary with different ethnic and geographical factors. In the west predominant
aetiology is alcohol and NASH (Non-alcoholic Steatohepatitis), whereas in developing countries alcohol and hepatitis B and C are
common aetiologies.
The aim of the study was to determine the aetiology, presentations and complications of cirrhosis of liver in a tertiary care
hospital in Karnataka.

\section{MATERIALS AND METHODS}

Six hundred and fifty consecutive patients with cirrhosis of liver attending the outpatient department of Medical Gastroenterology Department, Victoria Hospital from April 2014 to March 2015 were included in the study. All the presenting features, aetiology and complications were studied.

\section{RESULTS}

Mean age of the patients was $43.6 \pm 11.2$ years; $502(77 \%)$ patients were males and $148(23 \%)$ patients were females. Most common aetiology of cirrhosis was alcohol related (70\%) followed by Hepatitis B (7\%), Hepatitis C (3\%) and NASH (2\%). Cryptogenic cirrhosis accounted for $15 \%$ of cases. Most common presenting symptoms were pedal oedema, abdominal distension, gastrointestinal bleeding, jaundice and altered sensorium. Commonly seen complications were ascites (82\%), variceal bleeding (38\%), hepatic encephalopathy (16.5\%), SBP (3\%), HRS (2.5\%) and HCC (1.5\%). Child C cirrhosis was seen in 45\% patients, child B in 35\% and child A in 20\% patients. Mean MELD score was 16.8 \pm 7.6. MELD score of more than 19 was seen in $40 \%$ patients.

\section{CONCLUSION}

Cirrhosis is more common in males. The commonest cause of cirrhosis is alcohol related. Majority of patients present in advanced stage. With proper education, this form of cirrhosis can be prevented.

\section{KEYWORDS}

Cirrhosis, Alcohol, Aetiology, Complications, Hepatitis B, Hepatitis C.

HOW TO CITE THIS ARTICLE: Jain PK, Hemachandra P. Aetiology and clinical profile of cirrhosis of liver in a tertiary care centre of Karnataka. J. Evolution Med. Dent. Sci. 2016;5(81):6064-6066, DOI: 10.14260/jemds/2016/1369

BACKGROUND
Cirrhosis is defined by the World Health Organisation (WHO) as a diffuse process characterised by fibrosis and the conversion of normal liver architecture into structurally abnormal nodules. In cirrhosis, normal liver is replaced by fibrotic tissue and regenerative nodules leading to progressive loss of liver function. [1] Cirrhosis is an important cause of mortality and morbidity.[2]

The clinical presentation of cirrhosis is variable depending on the aetiology and whether the hepatocellular or portal hypertension predominates.[3] The diagnosis of cirrhosis is based on the clinical features, laboratory investigations,

Financial or Other, Competing Interest: None.

Submission 15-09-2016, Peer Review 29-09-2016,

Acceptance 01-10-2016, Published 10-10-2016.

Corresponding Author:

Dr. Parvesh Kumar Jain,

Associate Professor,

Department of Medical Gastroenterology,

Centenary Building, Victoria Hospital,

Near City Market, Fort Road,

Bangalore-560002.

E-mail: drjainpravesh1@gmail.com, jainpravesh1@rediffmail.com DOI: $10.14260 /$ jemds/2016/1369

(c) $($ ) $\$$ radiologic features and histology. Cirrhosis can be asymptomatic or present with complications like ascites, spontaneous bacterial peritonitis (SBP), Hepatorenal Syndrome (HRS), variceal haemorrhage, hepatic encephalopathy and Hepatocellular Carcinoma (HCC). In the West, predominant aetiology is alcohol and NASH. In developing countries along with alcohol viral hepatitis B and C are still common causes of cirrhosis.[4] Other rare causes of cirrhosis are Wilson's disease, Haemochromatosis, primary biliary cirrhosis, primary sclerosing cholangitis and Alpha-1antitrypsin deficiency.[5] The profile of cirrhosis may vary with different age and ethnic groups, geographical, social and aetiological factors. This study was conducted in a tertiary care hospital of Karnataka to determine the aetiology and clinical profiles of patients with cirrhosis of liver.

\section{MATERIALS AND METHODS}

This prospective observational study was carried out from April 2014 to March 2015, on patients attending the outpatient department of Medical Gastroenterology Department of Victoria Hospital, attached to Bangalore Medical College and Research Institute. Six hundred and fifty consecutive patients with cirrhosis were included in the study. Clinical cirrhosis was defined as a patient having at least one sign of hepatocellular failure,[6] one of portal hypertension[7] along 
with at least three ultrasound findings suggestive of cirrhosis of liver ${ }^{[8,9]}$ and/or liver biopsy evidence of cirrhosis in permissible cases. After informed consent, detailed history and clinical examination was done. Relevant blood investigations including complete blood count, liver function tests, renal function tests, serum electrolytes, fasting and postprandial blood sugar, Prothrombin Time (PT), serum ammonia, Hepatitis B and C serology were done. Abdominal ultrasound and Upper Gastrointestinal (UGI) endoscopy was done in all the patients. In patients with suspected liver space occupying lesion, CT/MRI abdomen was done. The severity of disease was assessed by Child Turcotte Pugh criteria and MELD score.

The diagnosis of alcoholic cirrhosis was made on the basis of history of alcohol consumption more than $80 \mathrm{~g} / \mathrm{dL}$ in men and more than $40 \mathrm{~g} / \mathrm{dL}$ in women for 10 years.[10] Hepatitis B and $C$ related cirrhosis were diagnosed based on serological tests like HBsAg, Anti-HCV, HBV DNA and HCV RNA. Autoimmune Hepatitis was diagnosed based on the International Diagnostic Criteria for the diagnosis of Autoimmune Hepatitis.[11] NASH related cirrhosis was diagnosed based on presence of cirrhosis in patients with evidence of BMI $>28 \mathrm{~kg} / \mathrm{m} 2$, diabetes, negative viral markers, alcohol less than $20 \mathrm{gm} /$ day in men and $<10 \mathrm{gm} /$ day in females and histological features like lobular or portal inflammation, ballooned hepatocytes with Mallory Denk bodies and fibrosis in a pericentral vein or zone 3 distribution. In absence of liver biopsy, even with probable NASH patients were categorised as cryptogenic cirrhosis. Diagnosis of cryptogenic cirrhosis was made on the basis of exclusion of all known causes of cirrhosis.

Diagnostic ascitic fluid tapping was done in all the patients on first visit. Ascitic fluid was collected in Ethylene Diamine Tetra Acetic acid (EDTA) tube for Total Leucocyte Count (TLC) and Differential Leucocyte Count (DLC) and in plain vial for protein, albumin and sugar. Spontaneous Bacterial Peritonitis (SBP) was diagnosed if ascitic fluid analysis showed total Polymorph Nuclear (PMN) cell count: > 250 cells/ $\mathrm{mm}^{3}{ }^{\text {.[12] }}$

Hepatic encephalopathy was diagnosed on basis of history, West Haven's criteria and number connection test A and B.[13] Hepatorenal Syndrome (HRS) was diagnosed in cirrhotics with ascites with serum creatinine $>1.5 \mathrm{mg} / \mathrm{dL}$, no improvement of ascites after at least 2 days of diuretic and plasma expansion, absence of shock and other parenchymal kidney disease.[14] Gastroesophageal varices were detected and graded by endoscopy.[15] HCC was diagnosed by radiology and/or the presence of high alpha fetoprotein $(>200 \mathrm{ng} / \mathrm{mL})$ in the setting of a mass in a cirrhotic liver.[16] Data were recorded on a predesigned proforma and managed on Microsoft Excel spreadsheet. Continuous variables were summarised by means and standard deviations. All statistical analysis was carried out by SPSS software.

\section{RESULTS}

Six hundred and fifty patients with cirrhosis were enrolled in the study; 502 (77\%) patients were males and 148 (23\%) patients were females. Mean age of the patients was $43.6 \pm 11.2$ years. Baseline laboratory parameters of the study population are shown in Table 1. Most common aetiology of cirrhosis was alcohol related (70\%) followed by Hepatitis B (7\%), Hepatitis C $(3 \%)$ and NASH (2\%). Cryptogenic cirrhosis accounted for $15 \%$ of cases. Other causes of cirrhosis were Wilson's disease, autoimmune hepatitis and Budd-Chiari syndrome (Table 2). Most common presenting symptoms were pedal oedema, abdominal distension, gastrointestinal bleeding, jaundice and altered sensorium (Table 3).

Ultrasound examination showed cirrhotic changes in 95\% patients. Other findings were splenomegaly in $81 \%$, ascites in $78 \%$ and portal vein thrombosis in $10 \%$ patients. UGI endoscopy showed small varices in $25 \%$ patients and large varices in $35 \%$ patients. Fundal varices were seen in $3 \%$ of patients. Other findings on endoscopy were portal hypertensive gastropathy (90\%), duodenal ulcer (3\%) and gastric ulcer (2\%). Liver biopsy was done in 30 patients (4.61\%). Among the patients who underwent liver biopsy, 18 patients $(60 \%)$ had cryptogenic cirrhosis, 6 patients $(20 \%)$ had NASH and 3 patients (10\%) had autoimmune hepatitis. Commonly seen complications were ascites (82\%), variceal bleeding (38\%), hepatic encephalopathy (16.5\%), SBP (3\%), HRS (2.5\%) and HCC (1.5\%).

Child C cirrhosis was seen in 45\% patients, child B in 35\% and child $A$ in $20 \%$ patients. Mean MELD score was 16.8 \pm 7.6 ; $60 \%$ patients had MELD scores between $10-19,25 \%$ patients had MELD scores between 20-29 and 15\% patients had MELD score of more than 30 indicating advanced disease.

\begin{tabular}{|c|c|}
\hline Parameter & Mean \pm SD \\
\hline Haemoglobin (mg/dL) & $8.64 \pm 2.64$ \\
\hline TLC (mm³) & $6550 \pm 5540$ \\
\hline Platelet Count (lakh.cmm) & $1.34 \pm 0.46$ \\
\hline Urea (mg/dL) & $42.4 \pm 28.4$ \\
\hline Creatinine (mg/dL) & $1.36 \pm 1.4$ \\
\hline Sodium (mmol/L) & $134.3 \pm 7.3$ \\
\hline Potassium (mmol/L) & $3.4 \pm 1.6$ \\
\hline RBS (mg/dL) & $110.4 \pm 44$ \\
\hline T. Bilirubin (mg/dL) & $5.45 \pm 6.46$ \\
\hline D. Bilirubin (mg/dL) & $3.24 \pm 2.84$ \\
\hline AST (U/L) & $118 \pm 98.6$ \\
\hline ALT (U/L) & $64 \pm 84.4$ \\
\hline T. Protein (mg/dL) & $5.84 \pm 1.45$ \\
\hline Albumin (g/dL) & $2.34 \pm 0.54$ \\
\hline Alkaline phosphatase (IU/mL) & $216.6 \pm 164.5$ \\
\hline GGT (U/L) & $156 \pm 284.6$ \\
\hline PT (sec) & $18.34 \pm 6.96$ \\
\hline INR & $1.68 \pm 0.68$ \\
\hline Table 1: Biochemistry Findings of Study Population \\
\hline
\end{tabular}

\begin{tabular}{|c|c|}
\hline Aetiology & Number (\%) \\
\hline Ethanol Related & $455(70 \%)$ \\
\hline Cryptogenic & $98(15 \%)$ \\
\hline Hepatitis B & $46(7 \%)$ \\
\hline Hepatitis C & $20(3 \%)$ \\
\hline NASH & $13(2 \%)$ \\
\hline Wilson's Disease & $6(1 \%)$ \\
\hline Autoimmune & $6(1 \%)$ \\
\hline Budd-Chiari Syndrome & $6(1 \%)$ \\
\hline Table 2: Aetiology of Cirrhosis in Study Population \\
\hline
\end{tabular}

\begin{tabular}{|c|c|}
\hline Symptoms & (\%) \\
\hline Abdominal Distension & $74.3 \%$ \\
\hline Pedal Oedema & $70 \%$ \\
\hline Hematemesis & $43.4 \%$ \\
\hline Jaundice & $36.3 \%$ \\
\hline Altered Sensorium & $20.3 \%$ \\
\hline Table 3: Clinical Features of Study Population \\
\hline
\end{tabular}




\section{DISCUSSION}

Cirrhosis can occur at any age and affects both the sexes, often causing prolonged morbidity. Male predominance was seen in our study with a M:F ratio of 3.34:1 and was similar to findings noted in a study by Pathak O.K. et al, where $80.7 \%$ among 181 patients were males.[17] Higher incidence was also reported by Paul SB et al with a M:F ratio of 6.1:1 among cirrhotics.[18] This difference is due to high incidence of ethanol intake among men compared to women, which is the major aetiology of chronic liver disease and also due to differences in the medical care seeking practice among both sexes.

Most patients present late with advanced disease. Ascites (74.3\%), UGI bleeding (43.4\%), jaundice (36.3\%) and altered behaviour $(20.3 \%)$ were the commonest presentation in our study. Ascites and upper GI bleeding was the commonest complications in other studies too; in a study by Maskey R et al ascites was seen in $84.4 \%$ and upper GI bleeding in $35.5 \%$ of patients.[19] In another series by Md. Shahid Aziz et al, ascites was seen in $53.8 \%$ and upper GI bleed in $25.1 \%$ patients. ${ }^{[17]}$

While hepatitis B infection is more prevalent in the Asian and Sub-Saharan Africa in our study cirrhosis was mostly alcohol related (70\%). Alcohol was the commonest aetiology in a study by R Maskey et al.[19] However, in a study from Pakistan, the common aetiologies were due to HCV (67.7\%) and HBV (18\%).[20]

Complications noted in our study were similar to those observed in a study by Hamzullah Khan et al which showed ascites in $27.86 \%$, variceal bleeding in $18.03 \%$, HRS in $3.27 \%$ and HCC in $1.63 \%$ patients.[21]

In our study Child C cirrhosis was seen in $45 \%$ patients, Child B in 35\% and Child A in 20\% patients. In a study by Md. Shahid Aziz et al Child A cirrhosis was seen 39.5\%, Child B in $35.3 \%$ and Child $\mathrm{C}$ in $25.1 \%$ patients.[20] In a study by Hamzullah Khan et al, majority of patients had Child A cirrhosis (83.3\%).[21] This was probably due to the fact that majority of patients had viral infection and hence moderate disease whereas majority of our patients had alcohol related cirrhosis.

\section{CONCLUSION}

Alcohol related cirrhosis is the most common cause of cirrhosis in our institute. Majority of patients present at advanced stage. With proper education and legislation, this form of cirrhosis can be prevented.

\section{REFERENCES}

1. Anthony PP, Ishak KG, Nayak NC, et al. The morphology of cirrhosis. Recommendations on definition, nomenclature, and classifications by a working group sponsored by the World Health Organization. J Clin-Pathol 1978;31(5):395414.

2. Bellentani S, Tiribelli C. The spectrum of liver disese in the general population: lesson from the dionysos study. J Hepatol 2001;35(4):531-7.

3. Kasper D, Fauci A, Longo D, et al. Cirrhosis and its complications. In: Raymond T, Chug, Podolsky DK, eds. Harrison's principles of internal medicine. $15^{\text {th }}$ edn. New York: Mc Graw Hill 2001:1754-6.

4. Aiden P, Mc Cormick. Hepativ Cirrhosis. In: Sherlock's diseases of the liver and biliary system. $12^{\text {th }}$ edn. Wiley Blackwell 2011:103-120.
5. Kim WR, Gross JB, Proterucha JJ, et al. Outcome of hospital care of liver disease associated with Hepatitis C in the US. Hepatology 2001;33(1):201-6.

6. Sherlock S, Dooley J. Hepatocellular failure. In: Disease of liver and biliary system. 10 $10^{\text {th }}$ edn. Oxford: Blackwell Science 1997:81-5.

7. Sherlock S, Dooley J. The portal venous system and portal hypertension. In: Disease of liver and biliary system. 10 $10^{\text {th }}$ edn. Oxford: Blackwell Sciences 1997:110-40.

8. Tehelepi H, Ralls PW, Radin R, et al. Sonography of diffuse liver disease. J Ultrasound Med 2002;21(9):1023-32.

9. Richard MG. Diffuse liver disease In: Textbook of gastrointestinal radiology. $10^{\text {th }}$ edn. Philadelphia: WB Saunders 1994:100-8.

10. Kasper D, Fauci A, Longo D, et al. Alcoholic liver disease. In: Malliard ME, ed. Harrison's principle of internal medicine. ${ }^{\text {th }}$ edn. New York: Mc-Graw Hill 2001:1752-4.

11. Alvarez F, Berg PA, Bianchi FB, et al. International autoimmune hepatitis group report: review of criteria for diagnosis of autoimmune hepatitis. J Hepatol 1999;31(5):929-38.

12. Rimola A, Garcia-Tsao G, Navasa M, et al. Diagnosis, treatment and prophylaxis of spontaneous bacterial peritonitis : a consensus document. International Ascites Club J Hepatol 2000;32(1):142-53.

13. Ferenci P, Lockwood A, Mulle $K$, et al. Hepatic encephalopathy-definition, nomenclature, diagnosis and quantification: final report of the working party at the $11^{\text {th }}$ world congress of gastroenterology, Veinna, 1998. Hepatology 2002;35(3):716-21.

14. Salerno F, Gerbes A, Gines P, et al. Diagnosis, prevention and treatment of hepatorenal syndrome in cirrhosis. A consensus workshop of the international ascites club. GUT 2007;56:1310-8.

15. Conn HO. Ammonia tolerance in the diagnosis of esophageal varices. A comparison of endoscopic, radiological and biochemical techniques. J Lab Clin Med 1967;70(3):442-51.

16. Talwalkar JA, Gores GJ. Diagnosis and staging of hepatocellular carcinoma. Gastroenterology 2004;127(5 Suppl 1):S126-32.

17. Paathak OK, Paudel R, Panta OB, et al. Retrospective study of the clinical profile and prognostic indicators in patients of ALD admitted to a tertiary care teaching hospital in West Nepal. Saudi J Gastroenterol 2009;15(3):171-5.

18. Paul SB, Sreenivas V, Gulati MS, et al. Incidence of hepatocellular carcinoma among Indian patients with cirrhosis of liver: an experience from a tertiary care centre in Northen India. Indian Journal of Gastroenterol 2007;26(6):274-8.

19. Maskey R, Karki P, Ahmed SV, et al. Clinical profile of patients with cirrhosis of liver in a tertiary care hospital, Dharan, Nepal. Nepal Med Coll J 2011;13(2):115-8.

20. Md Aziz S, Saed F, Md Farookh. Clinical spectrum of cirrhosis of liver: a study of 167 cases. Pakistan Armed Force Medical Journal 2009;59(4):433-6.

21. Khan $\mathrm{H}$, Zarif M. Risk factors, complications and prognosis of cirrhosis in a tertiary care hospital of Peshawar. Hepatitis Monthly 2006;6(1):7-10. 